\title{
Divalent ligand for intramolecular complex formation to streptavidin $\uparrow$
}

\author{
Joan-Antoni Farrera, ${ }^{a}$ Pedro Hidalgo-Fernández, ${ }^{a}$ Jurry M. Hannink, ${ }^{b}$ Jurriaan Huskens, ${ }^{c}$ \\ Alan E. Rowan, ${ }^{b}$ Nico A. J. M. Sommerdijk ${ }^{d}$ and Roeland J. M. Nolte ${ }^{b}$ \\ a Departament de Quimica Organica, Universitat de Barcelona, Martí i Franqués 1, 08028, \\ Barcelona, Spain.E-mail: jfarrera@ub.edu \\ ${ }^{b}$ Institute for Molecules and Materials, Radboud Universiteit Nijmegen, P.O. Box 9010, 6525, \\ ED Nijmegen, The Netherlands \\ ${ }^{c}$ Laboratory of Supramolecular Chemistry and Technology, MESA+ Institute for \\ Nanotechnology, University of Twente, P.O. Box 217, 7500, AE Enschede, The Netherlands \\ ${ }^{d}$ Laboratory for Macromolecular and Organic Chemistry, Eindhoven University of Technology, \\ P.O. Box 513, 5600, MB Eindhoven, The Netherlands
}

Received 25th April 2005, Accepted 17th May 2005

First published as an Advance Article on the web 24th May 2005

\begin{abstract}
Monovalent ligand 4 and divalent ligand 8 have been synthesized, and their thermodynamic parameters of complexation to avidin and streptavidin have been analyzed in terms of multivalent binding.
\end{abstract}

Avidin (Av) and streptavidin (SAv) are tetrameric proteins, wellknown for their high binding $\left(K_{\mathrm{a}} \approx 10^{15} \mathrm{M}^{-1}\right.$ and $2.5 \times 10^{13} \mathrm{M}^{-1}$, respectively) to biotin (BT), which has allowed to use them in many biochemical applications. ${ }^{1} \mathrm{X}$-Ray diffraction and binding studies of BT and analogues with Av and SAv have suggested a major contribution to binding of the ureido group of BT, with a lower contribution coming from the valerate side chain and the thiolane ring of BT. ${ }^{2,3}$ The formation of the complex $\mathrm{SAv}-\mathrm{BT}\left(\Delta G^{\circ}=-76.4 \mathrm{~kJ} \mathrm{~mol}^{-1}\right)$ is enthalpically driven $\left(\Delta H^{\circ}=\right.$ $\left.-134 \mathrm{~kJ} \mathrm{~mol}^{-1}\right)$, with an unfavorable contribution from entropy. ${ }^{3}$ Other ligands structurally not related to BT, e.g. azobenzene dyes such as 2-(4'-hydroxyphenylazo)benzoic acid (HABA) have been shown to bind to both $\mathrm{Av}$ and $\mathrm{SAv}$ at the same binding site as BT. However, in the case of HABA, the binding to SAv $\left(\Delta G^{\circ}=-22.0 \mathrm{~kJ} \mathrm{~mol}^{-1}\right)$ is not enthalpically driven $\left(\Delta H^{\circ}=\right.$ $\left.+7.1 \mathrm{~kJ} \mathrm{~mol}^{-1}\right){ }^{3}$

In most applications of the $\mathrm{SAv}-\mathrm{BT}$ system, ${ }^{4}$ for instance in the preparation of protein monolayers based on avidinpolymer amphiphiles, ${ }^{5}$ it is desirable to have a unique type of complex and a well-defined supramolecular architecture. This is usually accomplished by working under saturation conditions, where the four binding sites are occupied by derivatized BT molecules. However, in some specific applications, it can be difficult or even impossible to occupy the four binding sites of $\mathrm{SAv}$, leading to the formation of isomeric complexes as well as complexes of different stoichiometry. In this case the use of divalent ligands, i.e. those in which two units of a monovalent ligand are covalently linked via a spacer arm, could be advantageous owing to the smaller number of complexes they form with SAv. In order to design these divalent ligands, the optimal spacer length and polarity should be known. Previous works were based on bisbiotin compounds, which were shown to induce $\mathrm{Av}$ or $\mathrm{SAv}$ oligomerization when the length of the spacer was not optimal for the formation of the intramolecular complex. ${ }^{6,7}$ Unfortunately, the techniques used to detect the extent of oligomerization (electron microscopy and size exclusion chromatography) give no information about the stability of the intramolecular complex, and only give an indication of the length of the spacer that minimizes oligomerization. More

$\dagger$ Electronic supplementary information (ESI) available: Experimental details and binding models. See http://www.rsc.org/suppdata/ob/ b5/b505700k/ informative could be the use of divalent ligands having two units of a monovalent ligand of moderate binding affinity for Av and SAv. With these reversible ligands it should be possible to easily measure the binding constants of the complexes with Av and $\mathrm{SAv}$, giving an indication of how appropriate a given spacer is for each protein in order to form intramolecular complexes. ${ }^{8}$

For this purpose, monovalent ligand $\mathbf{4}$ and divalent ligand 8 have been designed and synthesized, and their binding parameters to $\mathrm{Av}$ and $\mathrm{SAv}$ measured. Ligand $\mathbf{4}$ is based on the dimethylpropanediurea bicyclic framework. Molecular clips based on this compound have recently been described as host molecules for neutral guests. ${ }^{9}$ Like BT, ligand $\mathbf{4}$ has a urea group that might allow the formation of similar hydrogen bonding interactions with the protein residues of the binding pockets of $\mathrm{Av}$ and SAv. Ligand $\mathbf{4}$ has also a valerate side chain that, as in BT, might contribute to the binding through hydrophobic interactions of the methylene groups and hydrogen bonding of the carboxylate group. But unlike BT, in $\mathbf{4}$ the valerate chain is bound to the bridgehead position, there is a second ureido group present in the molecule and the molecular framework is of the bicyclo[3.3.1] type with an isopropylidene group as the shortest bridge. Ligand 8 contains two units of the monovalent ligand 4 linked to glutamic acid through a diamine. The amino group of $\mathbf{8}$ is expected to increase its aqueous solubility at neutral $\mathrm{pH}$, allowing also further functionalisation of the molecule.

Ligand $\mathbf{4}$ was prepared in $90 \%$ overall yield by reacting methyl 7,7-dimethyl-6,8-dioxooctanoate with two equivalents of urea in toluene and TFA as a catalyst, followed by saponification. Ligand $\mathbf{8}$ was synthesized in $25 \%$ overall yield by condensation of $Z$ protected, activated glutamic acid to $N$-Boc-1,6-hexanediamine, followed by cleavage of the Boc group, condensation of the resulting diamine to ligand 4 with DPPA and cleavage of the $Z$ group (see Scheme 1 and Supporting Information $\dagger$ ).

The dye HABA was used to probe the binding of $\mathbf{4}$ and $\mathbf{8}$ to Av and SAv. This dye, in its unbound form, has an absorption maximum at $348 \mathrm{~nm}$, which shifts to $500 \mathrm{~nm}$ when bound to Av or SAv. ${ }^{10}$ Addition of $\mathbf{4}$ or $\mathbf{8}$ to an aqueous solution of HABA containing either $\mathrm{Av}$ or $\mathrm{SAv}$ resulted in a decrease in the absorption at $500 \mathrm{~nm}$ and a corresponding increase in the absorption at $348 \mathrm{~nm}$, proving that both $\mathbf{4}$ and $\mathbf{8}$ bind to the same binding sites as HABA and BT. Since the binding constants of HABA to Av and SAv were already known $\left(K_{\mathrm{a}}=1.7 \times 10^{5} \mathrm{M}^{-1}\right.$ and $7.3 \times 10^{3} \mathrm{M}^{-1}$, respectively), ${ }^{6-10}$ the binding constants of 4 and 8 to $\mathrm{Av}$ and SAv could be measured in spectrophotometric competition experiments with HABA. The obtained binding constants (Table 1) are lower than the binding constants of BT, which is not surprising considering the good fit of the natural ligand into the binding site in terms of van der Waals, 
<smiles>COC(C)CCCCC(=O)Cl</smiles>

1<smiles>CC(C)(C)C(=O)Oc1ccc([N+](=O)[O-])cc1</smiles>

5 (R: $\mathrm{PhCH}_{2} \mathrm{O}_{2} \mathrm{C}$-)<smiles>COCCCCC(=O)C(C)(C)C=O</smiles>

2

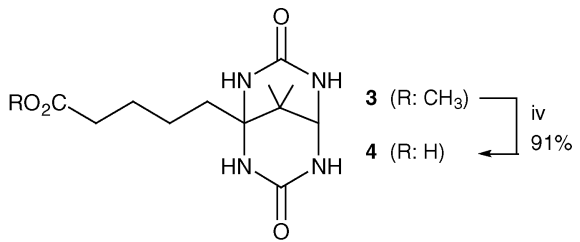

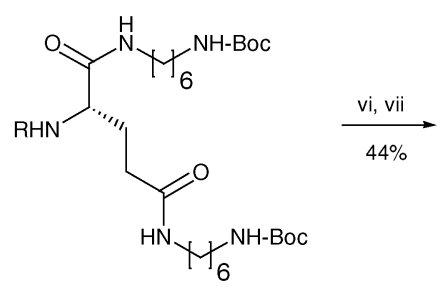

6 (R: $\mathrm{PhCH}_{2} \mathrm{O}_{2} \mathrm{C}-$ )

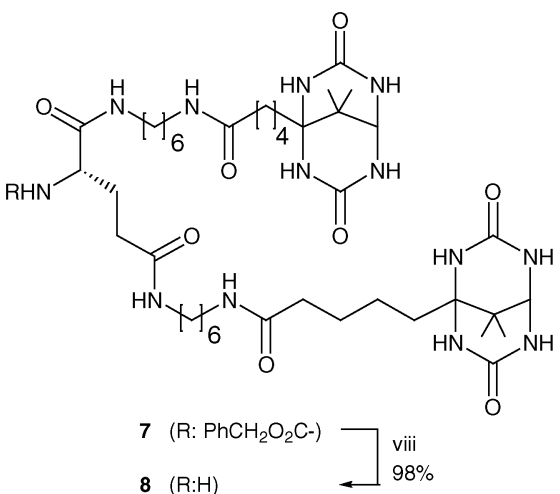

Scheme 1 Reagents and conditions: (i) $N$-(2-methyl-1-propenyl)morpholine; (ii) $\mathrm{H}_{2} \mathrm{O}$; (iii) $\mathrm{H}_{2} \mathrm{NCONH}_{2}$, TFA, toluene, $10 \mathrm{~h}$ reflux; (iv) $2 \mathrm{M} \mathrm{NaOH}$, reflux; (v) $\mathrm{H}_{2} \mathrm{~N}\left(\mathrm{CH}_{2}\right)_{6} \mathrm{NHBoc}$, AcOEt, rt, 48 h; (vi) TFA, rt, 1 h; (vii) DPPA, 4, Et ${ }_{3} \mathrm{~N}$, DMSO; (viii) $\mathrm{H}_{2}, \mathrm{Pd} / \mathrm{C}, \mathrm{MeOH}$.

Table 1 Binding constant and thermodynamic parameters of SAv and Av complexes in water ${ }^{a}$

\begin{tabular}{lllll}
\hline Complex & $K_{\mathrm{a}} / \mathrm{M}^{-1}$ & $\Delta G / \mathrm{kJ} \mathrm{mol}^{-1}$ & $\Delta H / \mathrm{kJ} \mathrm{mol}^{-1}$ & $T \Delta S / \mathrm{kJ} \mathrm{mol}^{-1}$ \\
\hline SAv-4 & $2.8 \times 10^{3 b}$ & $-19.7^{b}$ & $-8.4^{c}$ & +11.3 \\
SAv-8 & $1.1 \times 10^{6 b}$ & $-34.5^{b}$ & & \\
Av-4 & $5.3 \times 10^{5 b}$ & $-32.7^{b}$ & & \\
& $8.0 \times 10^{5}$ & $-33.7^{c}$ & $-11.7^{c}$ & +22.0 \\
Av-8 & $6.0 \times 10^{7 b}$ & $-44.4^{b}$ & & \\
& $1 \times 10^{7 c}$ & $-39.9^{c}$ & $+29.3^{c}$ & +69.2
\end{tabular}

${ }^{a} 298 \mathrm{~K}, \mathrm{pH}=7.3 .{ }^{b}$ Competition experiment with HABA as measured by spectrophotometry (estimated error on $\log K_{\mathrm{a}}$ of $\pm 5 \%$ ). ${ }^{c}$ Isothermal titration calorimetry.

hydrogen-bonding and hydrophobic interactions. Nevertheless, they are of the same order of magnitude as other ligands such as HABA.

In order to get further insight into the origin of the binding process, microcalorimetric titrations were performed on Av and SAv, and ligand 4. The thermodynamic parameters (Table 1) show that the formation of both complexes (Av-4 and SAv-4) has a large entropic contribution ( $65 \%$ and $57 \%$, respectively), an intermediate situation between the enthalpically driven binding of BT and the entropically driven binding of HABA. A large entropic contribution is usually an indication of the occurrence of hydrophobic interactions, and could be interpreted by the release of water molecules from the hydration shell of the ligand, as well as from the binding pocket. ${ }^{11}$ Reduction of rotational freedom of the valerate side chain of $\mathbf{4}$ upon binding to the protein should lead to a negative contribution to $\Delta S^{\circ}$. Interestingly, however, electrospray mass spectrometry in aqueous solution showed the presence of dimers and higher aggregates of 4. In these self-associated structures both the urea and the carboxylic acid groups are expected to be involved, as it is observed in the crystal structure of similar compounds. ${ }^{12}$ This self-association might also restrict the rotational freedom of the valerate side chain of the free ligand (4), leading to an almost neutral contribution to the $\Delta S^{\circ}$ of binding.

On the other hand, the small value for $\Delta H^{\circ}$ associated to the complexation of ligand $\mathbf{4}$, compared to BT, points to the formation of fewer and/or weaker hydrogen-bonds involving the ureido and the carboxylate groups of $\mathbf{4}$. This is probably the consequence of a less favourable orientation of the ligand inside the binding pocket due to steric repulsive interactions between the isopropylidene bridge of the ligand and protein residues at the binding site. London dispersion interactions between water molecules and apolar parts of the ligand, which will be lost in the complex with the protein, might also be partly responsible for the small enthalpic change of the binding.

It has been established that the minimal distance a fully extended spacer should span between two BT carboxylate carbonyls, in order to form an intramolecular complex to Av, is $25 \AA{ }^{6}$ In the case of SAv the minimal distance for intramolecular complex formation was determined to be $20 \AA . .^{13}$ The spacer in ligand $\mathbf{8}$, when fully extended, has a length of circa $27 \AA$ (measured between the amide carbonyls), which should be enough to allow the formation of an intramolecular complex with both Av and SAv. Size exclusion chromatography and light scattering measurements of a mixture of ligand $\mathbf{8}$ and $\mathrm{SAv}$ (or $\mathrm{Av}$ ) did not show any indication of oligomer formation.

The spectrophotometric titration curve of SAv with $\mathbf{8}$, in competition with HABA, was fitted to a 1 : 1 binding model corresponding to the formation of the divalent (intramolecular) complex assuming independent binding. The binding constant for the simultaneous binding of both units of dimethylpropanediurea to half SAv (two proximal binding sites) amounted to $1.1 \times 10^{6} \mathrm{M}^{-1}$. From this value and the intrinsic binding constant $\left(K_{\mathrm{i}}\right)$ of $2.8 \times 10^{3} \mathrm{M}^{-1}$ an effective molarity $(\mathrm{EM})$ of $70 \mathrm{mM}$ is calculated. Based on the $20 \AA$ distance between proximal binding sites in SAv, a divalent ligand of optimal length is estimated to generate an effective concentration $^{8-14}$ for the second binding $\left(C_{\text {eff }}\right)$ of approximately $99 \mathrm{mM}$. This value, together with the corresponding $K_{\mathrm{i}}$, leads to a higher limit of $1.6 \times 10^{6} \mathrm{M}^{-1}$ for the expected binding constant of $\mathrm{SAv}$ to an optimal divalent ligand based on $\mathbf{4}$, assuming independent binding. The fact that the experimental binding constant of $\mathbf{8}$ to $\mathrm{SAv}$ is so close to this higher limit suggests that the length of the spacer in $\mathbf{8}$ is appropriate to induce intramolecular complexation to SAv.

On the other hand, the spectrophotometric titration curve of Av with 8 in competition with HABA, fitted to the same 1 : 1 binding model (Fig. 1), gave a binding constant of $6.0 \times$ $10^{7} \mathrm{M}^{-1}$. From this value and the $K_{\mathrm{i}}$ of $5.3 \times 10^{5} \mathrm{M}^{-1}$, an $\mathrm{EM}$ of $0.11 \mathrm{mM}$ is calculated. In the case of $\mathrm{Av}$, considering the distance of approximately $25 \AA$ between proximal binding 


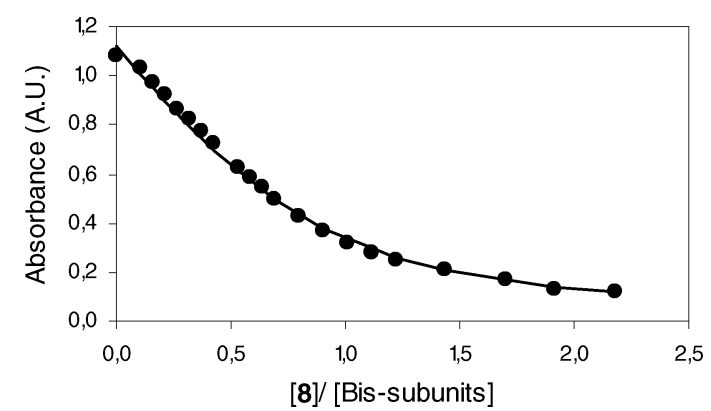

Fig. 1 Absorption change at $500 \mathrm{~nm}$ in the titration of $\mathrm{Av} 8.7 \times 10^{-6} \mathrm{M}$ and HABA $8.1 \times 10^{-5} \mathrm{M}$ with ligand 8 . Phosphate buffer $0.1 \mathrm{M}, \mathrm{pH}=$ 7.3. The solid line represents the fit of the data to the $(1: 1)$ binding model.

sites, a divalent ligand of optimal length is estimated to generate a $C_{\text {eff }}$ of about $51 \mathrm{mM}$. This $C_{\text {eff }}$ value, together with the corresponding $K_{\mathrm{i}}$, leads to a higher limit of about $2.9 \times 10^{10} \mathrm{M}^{-1}$ for the expected binding constant of Av to an optimal divalent ligand based on $\mathbf{4}$, assuming independent binding. The fact that the experimental binding constant is about 400 times lower than this higher limit suggest that the spacer of the divalent ligand could still be improved in order to induce intramolecular complexation to Av. The thermodynamic parameters (Table 1), obtained in a microcalorimetric titration experiment, show that the complexation of $\mathbf{8}$ to $\mathrm{Av}$ is strongly entropy-driven, with an endothermic change in enthalpy of $29 \mathrm{~kJ} \mathrm{~mol}^{-1}$. This severe enthalpy loss of the divalent ligand complexation compared to the monovalent ligand complexation suggests that the fit of the dimethylpropanediurea units of $\mathbf{8}$ into the binding sites is less tight than in the case of the monovalent ligand complex. It may also be that the spacer needs to be so close to the protein surface that both species are dehydrated strongly, leading to an endothermic enthalpy contribution but a gain in entropy. The change in entropy for the complexation of $\mathbf{8}$ to Av is more than twice the value found for the complexation of $\mathbf{4}$ to $A v$, suggesting that the restrictions in orientation of the spacer upon complexation are more than compensated by the proposed dehydration of both spacer and protein surface. The data in Table 1 suggests that, in order to induce intramolecular complexation to Av, a divalent ligand with a longer spacer might be more appropriate. This aspect is currently under investigation.

\section{Acknowledgements}

This research was supported by Generalitat de Catalunya (2001SGR00045 and 2002BEAI400180), by Ministerio de Ciencia y Tecnologia (BQU2002-02424) of Spain, and by the Netherlands Science Foundation (NWO-CW).

\section{References}

1 M. Wilchek and E. A. Bayer, Methods Enzymol., 1990, 184, 5.

2 N. M. Green, Adv. Protein Chem., 1975, 29, 85.

3 (a) P. C. Weber, D. H. Ohlendorf, J. J. Wendoloski and F. R. Salemme, Science, 1989, 243, 85; (b) P. C. Weber, J. J. Wendoloski, M. W. Pantoliano and F. R. Salemme, J. Am. Chem. Soc., 1992, 114, 3197; (c) P. C. Weber, M. W. Pantoliano, D. M. Simons and F. R. Salemme, J. Am. Chem. Soc., 1994, 116, 2717.

4 (a) H. Ebato, J. N. Herron, W. Müller, Y. Okahata, H. Ringsdorf and P. Suci, Angew. Chem., Int. Ed. Engl., 1992, 31, 1087; (b) W. Müller, H. Ringsdorf, E. Rump, G. Wildburg, X. Zhang, L. Angermaier, W. Knoll, M. Liley and J. Spinke, Science., 1993, 262, 1706.

5 J. M. Hannink, J. J. L. M. Cornelissen, J. A. Farrera, P. Foubert, F. C. De Schryver, N. A. J. M. Sommerdijk and R. J. M. Nolte, Angew. Chem., Int. Ed., 2001, 40, 4732.

6 N. M. Green, Methods Enzymol., 1990, 184, 51.

7 (a) D. M. Taylor, H. Fukushima and H. Morgan, Supramol. Sci., 1995, 2, 75; (b) D. S. Wilbur, P. M. Pathare, D. K. Hamlin and S. A. Weerawarna, Bioconjugate Chem., 1997, 8, 819; (c) K. J. Hamblett, B. B. Kegley, D. K. Hamlin, M.-K. Chyan, D. E. Hyre, O. W. Press, D. S. Wilbur and P. S. Stayton, Bioconjugate Chem., 2002, 13, 588.

8 (a) R. H. Kramer and J. W. Karpen, Nature., 1998, 395, 710; (b) P. I. Kitov, H. Shimizu, S. W. Homans and D. R. Bundle, J. Am. Chem. Soc., 2003, 125, 3284 .

9 (a) R. J. Jansen, A. E. Rowan, R. de Gelder, H. W. Scheeren and R. J. M. Nolte, Chem. Commun., 1998, 121; (b) R. J. Jansen, R. de Gelder, A. E. Rowan, H. W. Scheeren and R. J. M. Nolte, J. Org. Chem., 2001, 66, 2643.

10 N. M. Green, Biochem. J., 1965, 94, 23c

11 (a) W. Blokzijl and J. B. F. N. Engberts, Angew. Chem., Int. Ed. Engl., 1993, 32, 1545; (b) S. Otto and J. B. F. N. Engberts, Org. Biomol. Chem., 2003, 1, 2809.

12 K. A. Lyssenko, D. G. Gov, A. N. Kravchenko, I. E. Chikunov, O. V. Lebedev and N. N. Makhova, Mendeleev Commun., 2004, 1.

13 W. A. Hendrickson, A. Pahler, J. L. Smith, Y. Satow, E. A. Merritt and R. P. Phizackerley, Proc. Natl. Acad. Sci. USA, 1989, 86, 2190.

14 (a) A. Mulder, T. Auletta, A. Sartori, S. Del Ciotto, A. Casnati, R. Ungaro, J. Huskens and D. N. Reinhoudt, J. Am. Chem. Soc., 2004, 126, 6627; (b) A. Mulder, J. Huskens and D. N. Reinhoudt, Org. Biomol. Chem., 2004, 2, 3409. 